\title{
A GRAVIDEZ NA ADOLESCÊNCIA E A FEMINIZAÇÃO DA POBREZA A PARTIR DE RECORTES DE CLASSE, GÊNERO E RAÇA
}

\author{
PREGNANCY IN ADOLESCENCE AND THE FEMINIZATION OF \\ POVERTY FROM CLASS, GENDER AND RACE DELIMITATIONS
}

\author{
Marli Marlene Moraes da Costa ${ }^{\mathrm{I}}$ \\ Maria Victória Pasquoto de Freitas ${ }^{\text {II }}$
}

\begin{abstract}
I Universidade de Santa Cruz do Sul, Santa Cruz do Sul, RS, Brasil. Doutora em Direito. E-mail: marlim@unisc.br

${ }^{\text {II } U n i v e r s i d a d e ~ d e ~ S a n t a ~ C r u z ~ d o ~ S u l, ~}$ Santa Cruz do Sul, RS, Brasil. Mestra em Direito. E-mail: victoriapasquoto@ hotmail.com
\end{abstract}

Resumo: A análise da gravidez precoce e da feminizaçáo da pobreza a partir de recortes de classe, gênero e raça, permite com que se localize em que contextos, realmente, encontram-se as meninas grávidas. O problema de pesquisa compreende-se no questionamento: "Qual a influência da gravidez precoce na feminizaçáo da pobreza?" O objetivo geral foi analisar os fatores socioculturais associados ao desejo de ser mãe na adolescência e os objetivos específicos foram identificar os impactos sociais da gravidez precoce e verificar os problemas econômicos advindos da gravidez nessa fase do desenvolvimento da menina a partir da perspectiva de classe, gênero e raça; cada objetivo corresponde a um subcapítulo, respectivamente. $\mathrm{O}$ método de pesquisa adotado foi o dedutivo, partindo de premissas gerais e direcionando-se para temáticas específicas, com procedimento monográfico e técnica de pesquisa de documentação indireta, através da pesquisa bibliográfica e documental. Os resultados preliminares da pesquisa apontam que meninas pobres, com limitadas oportunidades educacionais e laborais e de cor negra compóem, em maioria, o grupo de adolescentes grávidas e de mulheres em um ciclo de pobreza extrema no Brasil.

Palavras-chave: Gravidez na adolescência. Feminização da pobreza. Classe, gênero e raça.

Abstract: The analysis of early pregnancy and the feminization of poverty based on class, gender and race cuts, allows us to locate the contexts in which pregnant girls actually find themselves. The research problem is understood in the question: "What is the influence of early pregnancy on the feminization of poverty?" The general objective was 
to analyze the sociocultural factors associated with the desire to be a mother in adolescence and the specific objectives were to identify the social impacts of early pregnancy and verify the economic problems arising from pregnancy at this stage of the girl's development from the perspective of class, gender and race; each objective corresponds to a subchapter, respectively. The research method adopted was the deductive one, starting from general premises and focusing on specific themes, with a monographic procedure and indirect documentation research technique, through bibliographical and documentary research. The preliminary results of the research show that poor girls, with limited educational and work opportunities, and who are black make up, in the majority, the group of pregnant teenagers and women in a cycle of extreme poverty in Brazil.

Keywords: Teenage pregnancy. Feminization of poverty. Class, gender and race.

\section{Introdução}

Ae emocional de meninos e meninas, alteram o seu comportamento, porque seus sentimentos ainda não estão maduros e o conhecimento da função sexual é praticamente inexistente. No período da adolescência, surge o interesse sexual e a afetividade, normalmente acompanhados de insegurança, ansiedade, timidez, instabilidade, angústia de não ser mais criança, mas por outro lado, ainda não é adulto. Inseguro quanto aos rumos do futuro, o (a) jovem enfrenta o mundo que lhe parece hostil, refugiando-se na timidez ou expandindo seu temperamento, conforme sejam as circunstâncias nas quais esteja inserido(a) no mundo da vida.

Tem-se que a família é o primeiro elemento socializador do ser humano, porque é a partir do grupo familiar que formará a sua estrutura de personalidade, aprenderá o que é certo ou errado, o que pode ou náo fazer, os limites para exercício de sua liberdade com responsabilidade ética e moral. As bases de sustentação familiar será seu ponto de referência nos desafios que enfrentará no meio social, pois relacionará tudo o que aprendeu com o que encontrar pela frente.

Não possuindo a maturidade para discernimento, e estando fascinado(a) pelas oportunidades encantadoras que lhe surgem, atira-se aos novos desafios sem dar-se conta dos riscos e comprometimentos que passam a existir.

$\mathrm{O}$ advento do anticoncepcional e dos fortes movimentos feministas, conferiram a mulher certa autonomia e escolha pela maternidade, o que corroborou para que a gravidez fosse, cada vez mais, um planejamento de vida, ao invés de um acontecimento natural. A análise da gravidez precoce e da feminização da pobreza a partir de recortes de classe, gênero e raça, possibilitou a localização dos contextos em que estão inseridas as meninas grávidas.

Os fatores socioeconômicos também são determinantes, meninas pobres, com limitadas oportunidades educacionais e laborais, vivendo em situação de violência em casa, ou mesmo num 
exercício de repetiçôes de papéis, isto é, que possuem mães e avós que foram mães adolescentes, tem uma tendência maior a serem mães precocemente. Todos esses fatores, acrescidos ao recorte de raça, demonstram que no Brasil, a maioria das meninas grávidas são pobres e negras.

Os desdobramentos da reprodução precoce e a limitação das já escassas oportunidades, vem construindo o fenômeno da feminização da pobreza e fazendo com que milhares de meninas e mulheres fiquem presas num ciclo de privações de renda, de educação e de sociabilidade. $\mathrm{O}$ que, em uma última análise, transforma-se em uma privação de liberdade, de desenvolvimento e de emancipação feminina no Brasil.

\section{Fatores socioculturais associados ao desejo de ser mãe na adolescência}

O século XXI trouxe consigo novas perspectivas de gênero. A ampliação dos movimentos feministas, o ingresso efetivo da mulher no mercado de trabalho, no âmbito educacional e na vida pública e o reconhecimento de direitos de igualdade, permitiram que meninas e mulheres ganhassem mais autonomia em suas escolhas e objetivos. Contudo, diversos fatores culturais engendrados socialmente permaneceram, a gravidez na adolescência deve ser analisada sobre múltiplos enfoques e não somente como uma vulnerabilidade ou fator prejudicial à adolescência. Milhares de meninas em todo mundo ficam grávidas todos os dias e muitas delas, planejam ou não se importam com a gravidez precoce, por isso é imprescindível a análise dos fatores socioculturais que criam o desejo de ser mãe na adolescência.

Os índices de fecundidade de meninas entre 15 e 19 anos de idade, são de 62 nascimentos a cada mil bebês nascidos vivos, ultrapassando a média mundial de 44 a cada mil. Isto é, cerca de 430 mil bebês nascem de máes adolescentes por ano. ${ }^{1}$ Esses dados se chocam com a crescente onda de informação e universalização de métodos contraceptivos, provocando uma série de questionamentos de profissionais da saúde, da educação e das ciências sociais sobre os motivos que levam a milhares de adolescentes a engravidar.

A criação de anticoncepcionais, a adolescência vista sob a perspectiva de período de pleno desenvolvimento físico e mental e a supervalorização da educação nesse período, fez com que o desejo de ser mãe se tornasse um projeto racional e optativo e a gravidez passou de um acontecimento natural da vida humana, para uma escolha. "A sociologia tem se indagado por que e como certas situaçóes e fenômenos, em determinada época e em um contexto social preciso, começam a ser vistos como "problemáticos"2

Hodiernamente, ainda existem meninas com vontade de ser mães precocemente, não obstante a existência de uma enxurrada de informações sobre contracepção e preservativos, o que vai em sentido oposto a expectativa social e médica quanto a trajetória a ser seguida pelas adolescentes.

A partir da análise da realidade de adolescentes grávidas pertencentes a camadas sociais mais pobres, se percebe que elas caminham em direção contrária as teses que apontam a

1 UNFPA. Situação da população mundial 2019: Um trabalho inacabado: a busca por direitos e escolhas para todos e todas. Brasil: 2019. Disponível em: <https://brazil.unfpa.org/pt-br/publications/situacao-da-populacao-mundial-2019>. Acesso em: 22 jun. 2020.

2 HEILBORN, Maria Luiza. et. al. O aprendizado da sexualidade: reprodução e trajetórias sociais de jovens brasileiros. Rio de Janeiro: Garamond e Fiocruz, 2006. p. 30 
problematização da gravidez precoce, uma eventual gravidez não representa um problema para elas, isto é, não é um fator a ser evitado na adolescência. Esse pensamento, como apontado por Nunes $^{3}$, se dá pela ausência de expectativas para o futuro, associada a carência de políticas sociais e de projetos educacionais e profissionais que produzam a vontade de mudança de vida nessas meninas. Diante dessa realidade, a maternidade se apresenta como um ideal a ser alcançado, como uma forma das meninas obterem reconhecimento e valorização social, além de se tornar uma das poucas possibilidades de projeção de um futuro melhor e de mobilidade de classes.

A gravidez não pode ser generalizada como um problema social ou "acidente de percurso" na vida de adolescentes irresponsáveis, como amplamente discutido na sociedade. É necessário problematizar a gravidez na adolescência, deslocando esse conceito para as diversas realidades sociais, "[...] tentando uma abordagem menos homogênea da questáo e procurando observar como a maternidade se insere nos projetos de vida das jovens mães, a partir de suas diferenças." ${ }^{4}$

"Vocês querem entender a gravidez na adolescência? Então é preciso olhar para além da nossa barriga, ouvir também nossa cabeça e nosso coração." A frase, formulada por um grupo de adolescentes brasileiras grávidas ou mães, é reveladora da complexidade que envolve o tema e sintetiza o sentimento das meninas quanto à forma com que são representadas pela sociedade. ${ }^{5}$

Abrindo uma fenda na bolha social que considera o adolescente apenas aquele indivíduo que deve necessariamente estar em fase de escolarização e/ou profissionalização para corresponder às expectativas sócio-familiares, existe uma parte de adolescentes, normalmente chamados de "problemáticos" que foge dessa curva de normalidade. A gravidez na adolescência se apresenta, principalmente, em cenários de pobreza e ausência de expectativas para o futuro, onde meninas sonham com a maternidade como uma forma de emancipar-se da família e ganhar maior autonomia. ${ }^{6}$

Em uma reportagem realizada pelo Profissão Repórter no ano de 2017 no Estado do Acre (um dos Estados com mais gravidez na adolescência), ficou demonstrado que algumas meninas e seus namorados/maridos pensavam a gravidez como uma "dádiva de Deus" ou haviam planejado, não utilizando qualquer método contraceptivo, alguns homens ainda afirmaram que utilizar anticoncepcional ou preservativo abria a possibilidade de traição, por isso não deixavam as mulheres utilizarem. ${ }^{7}$

A cultura, representada pelas açôes reiteradas por diversas geraçôes, também evidenciase quando se trata de gravidez na adolescência. A reprodução de vida familiar, isto é, mães adolescentes que também foram fruto de gravidez precoce, demonstram um traço cultural da gravidez na adolescência, uma vez que mesmo que as condiçóes de vida, saúde, informação e educação sejam diferentes, as meninas repetem a trajetória de vida de suas mães. A cultura da

3 NUNES, Silvia Alexim. Problematizando a gravidez na adolescência. Revista Epos. Rio de Janeiro, v. 1, n. 1, jan. 2010. Disponível em <http://pepsic.bvsalud.org/scielo.php?script=sci_arttext\&pid=S2178-700X2010000100004\&lng=pt\& nrm=iso $>$. Acesso em: 25 abr. 2020.

4 Ibidem, s/p.

5 SANTOS, Benedito Rodrigues; et al. Gravidez na adolescência no Brasil: Vozes de meninas e de especialistas. Brasília: Athalaia, 2017. Disponível em: <http://unfpa.org.br/Arquivos/br_gravidez_adolescencia_2017.pdf>. Acesso em 20 jun 2019. p. 11.

6 Ibidem.

7 PROFISSÃO REPÓRTER. Direção de Ali Kamel e Silvia Faria. Acre: Rede Globo, 2017, (17 min). Disponível em: <https://globoplay.globo.com/v/6340150/>. Acesso em 5 jun. 2020. 
gravidez precoce está tão presente, que até mesmo filhas de profissionais da saúde engravidam, quer dizer, a informaçáo e o diálogo familiar não fazem com que a adolescente seja mais consciente. ${ }^{8}$

As motivações para engravidar, segundo pesquisa de campo realizada no Ceará com adolescentes grávidas e mães, consistem no desejo de ser mãe - como um sonho - em primeiro lugar, seguidos pela ausência de prevenção, descuido, desconhecimento de métodos contraceptivos, para satisfazer o parceiro, para sair de casa e por sentir-se só. E a gravidez na adolescência representa primeiramente uma felicidade e realizaçáo pessoal para as meninas, em segundo lugar uma responsabilidade muito grande e em terceiro o começo de uma nova vida. A gravidez como um problema é citada por poucas adolescentes, que colocam diversos fatores positivos em ser mãe em primeiro lugar. ${ }^{9}$

O gosto por cuidar de crianças também serve como motivação para a maternidade precoce, para aquelas meninas que já cuidaram de seus irmãos mais novos. Para meninas que vivem num contexto onde suas mães deram a luz quando adolescentes e aceitam positivamente a gravidez precoce, há uma dupla dificuldade em fugir do destino da gravidez, mesmo que haja mais informação e acesso a métodos contraceptivos, o que demonstra o viés cultural como que imutável da gravidez na adolescência. ${ }^{10}$

Uma pesquisa realizada com adolescentes apontou que a maioria deles conhece os métodos contraceptivos e "[...] as principais justificativas para a ocorrência da gravidez foram: $51,2 \%$ queriam ser mães; $18,6 \%$ disseram que gostavam de crianças; 9,3\% referiram ser desejo do casal; e 4,7\% não queriam perder o parceiro." ${ }^{11}$

A análise das condições sociodemográficas das adolescentes pode influenciar em suas perspectivas sobre a gravidez precoce. Nas diversas pesquisas de campo realizadas, envolvendo majoritariamente meninas que vivem em contextos sociais de pobreza e marginalização, a gravidez apresenta-se como única oportunidade de mudança de status social e econômico. "Alguns fatores contribuem para a gravidez precoce, dentre eles a ingenuidade, a submissão, a violência, as dificuldades de obter algum método contraceptivo [...]." ${ }^{12}$

A decisão de ter um filho precocemente, não raramente é planejada e desejada tanto pela menina como por seu companheiro, com o objetivo de constituir uma família. Para a adolescente a maternidade representa amadurecimento e a transformaçáo de menina para mulher. A disparidade de idades entre a menina e seu companheiro ficam evidentes, meninas com quinze anos de idade engravidam de homens com mais de trinta anos. ${ }^{13} \mathrm{~A}$ diferença de

8 Ibidem.

9 NETO, Francisco Rosemiro Guimarães Ximenes; et al. Gravidez na adolescência: motivos e percepçóes de adolescentes. Revista brasileira de enfermagem. Brasília, v. 60, n. 3, p. 279-285, mai./jun. 2007. DOI: https:// doi.org/10.1590/S0034-71672007000300006. Disponível em:<http://www.scielo.br/scielo.php?script=sci_ arttext\&pid=S0034-71672007000300006\&lng=en\&nrm=iso $>$. Acesso em: 7 jun. 2020.

10 SANTOS, Cristiane Albuquerque C. dos; NOGUEIRA, Kátia Telles. Gravidez na adolescência: falta de informação?. Adolescência \& Saúde. v. 6, n. 1, p. 48-56, jan./mar. 2009. ISSN: 2177-5281. Disponível em: <https://s3-sa-east-1. amazonaws.com/publisher.gn1.com.br/adolescenciaesaude.com/pdf/v6n1a11.pdf. Acesso em: 25 abr. 2020.

11 Ibidem, p. 53.

12 RESTA, Darielli Gindri; et. al. Adolescentes: por quais motivos elas engravidam?. Revista de enfermagem UFPE. Recife, v. 8, n. 5, p. 1229-1236, mai. 2014. DOI: 10.5205/reuol.5863-50531-1-ED.0805201417. Disponível em: <https://periodicos. ufpe.br/revistas/revistaenfermagem/article/viewFile/9804/9971>. Acesso em: 7 jun. 2020. p. 1230.

13 Ibidem. 
idades também é um determinante, uma vez que quanto mais nova a adolescente, se supóe que seja mais imatura, ingênua e mais maleável aos desejos do companheiro; podendo engravidar somente para provar que o ama.

Adolescentes que classificaram sua gravidez como "aconteceu", sem planejamento ou desejo, afirmam que apesar de não planejarem, esse acontecimento fez com que suas vidas se tornasse muito mais feliz e equilibrada, embora não esperassem ter um filho, atribuem a ele somente sentimentos positivos e afirmam que será uma boa companhia afetiva para elas, como para suprir algum vazio em suas vidas. ${ }^{14}$

Os diversos motivos conscientes ou inconscientes para engravidar, contradizem o paradigma da gravidez na adolescência como indesejada ou não planejada. As desigualdades de gênero, também fazem com que o companheiro tenha maior poder de escolha sobre a vida do casal, sobretudo quando é o único provedor do lar, convencendo a menina de que é melhor para o casal ter um filho. ${ }^{15}$

No entanto, será que o desejo intenso de ter um filho é proveniente da necessidade de autorrealizaçáo como mulher ou uma válvula de escape da realidade vivenciada, decorrente da desestruturação familiar, de ambientes hostis e de situaçôes de violência domiciliar, seja no âmbito psicológico, físico ou mesmo sexual? A gravidez da adolescente era vista como uma forma de "dar solução" aos problemas enfrentados pela família de origem. Nesse sentido, a decisão de fugir dos problemas familiares era entendida como um refúgio das constantes brigas entre os pais e da violência doméstica. ${ }^{16}$

Uma oficina realizada no Brasil pelo Fundo das Naçôes Unidas para a Infância (UNICEF), Fundo de População das Nações Unidas (UNFPA) e o Instituto dos Direitos da Criança e do Adolescente (INDICA), reuniu especialistas, adolescentes grávidas e mães para tratar sobre a gravidez precoce sob seus diversos ângulos e opiniôes. Uma menina usou o termo "escapulir" para a gravidez, ou seja, a gravidez não fazia parte de seus planos para a adolescência e contrariamente à ideia de gravidez indesejada, amplamente disseminada no âmbito de saúde, da educação e meios midiáticos, as meninas preferem o termo não planejada como característica das circunstâncias de sua gravidez. ${ }^{17}$

A fala das grávidas e mães adolescentes na oficina é reveladora de como o gênero determina percepçóes e posiçóes. Elas reivindicam mais liberdade para viver sua sexualidade e avaliam que ainda existe muito preconceito e legitimaçáo da fala somente para os meninos, o que as deixa numa posição de inferioridade pelo medo de serem julgadas. ${ }^{18}$

As adolescentes também afirmaram que apesar de haver a disseminação da informação sobre sexualidade e seus riscos, não há acesso a métodos contraceptivos, seja pela ausência direta de medicamentos ou porque a família imputa restriçóes sexuais, não permitindo o acesso a preservativos e anticoncepcionais. É importante mencionar que a moral sexual se diferencia entre os gêneros, uma vez que para os meninos é considerado natural adquirir preservativos, recebendo até mesmo incentivo dos pais como afirmação da virilidade; enquanto que para meninas, adquirir

14 Ibidem.

15 Ibidem.

16 Ibidem, p. 1233.

17 SANTOS, B.R. Op. Cit..2017

18 Ibidem, p. 53. 
preservativos pode ser considerado um aspecto negativo, pois isso estaria afirmando sua atividade sexual. "Uma adolescente que passar num posto de saúde ou entrar numa farmácia para adquirir preservativos pode ser vista como 'fácil', 'fogosa' e mesmo 'prostituta." 19

As normas sociais ainda estruturam um comportamento passivo e recatado para as meninas e outro ativo para os meninos. Com isso, espera-se delas pouca expressão da sua sexualidade, cabendo aos meninos as iniciativas sexuais. Porém, contraditoriamente, recai sobre as meninas a responsabilidade pelos cuidados com a contracepção, o que exige delas uma atitude ambivalente, de recato e também de atitude. ${ }^{20}$

Um determinante para gravidez precoce, também relaciona-se ao diálogo familiar, isto é, a educação sexual familiar. Adolescentes que dialogam abertamente com seus pais, tem mais tendência em utilizar corretamente os métodos anticoncepcionais e, consequentemente, menor possibilidade de engravidar na adolescência. Dentre as meninas grávidas ou mães, há um consenso de que há certa imaturidade e ingenuidade quanto a utilização de anticoncepcionais e preservativos, seja porque elas náo estavam esperando ter relaçóes sexuais, porque achavam impossível engravidar, por esquecimento em tomar o anticoncepcional, e por falta de informaçóes sobre contracepção e reprodução e utilização dos métodos anticoncepcionais. ${ }^{21}$

Através das pesquisas foi possível identificar que normalmente a gravidez na adolescência é planejada quando a adolescente tem um companheiro, como uma forma de fortalecer o relacionamento. Uma abordagem realizada num ambulatório de pré-natal, demonstrou que a maioria das adolescentes grávidas pela segunda vez, vivia em situação conjugal com o pai do bebê, demonstrando um fator de risco para a repetição da gravidez. ${ }^{22}$ As afirmaçóes das adolescentes quanto a gravidez giram em torno da vinda do bebê como uma solução para seus problemas.

M1 - "Eu queria um filho, meu filho me deu outra razão para continuar vivendo"

M5- "Eu casei para ir embora de casa e não me arrependo, pois minha vida melhorou muito"

M 11- "Não tive opçấo: ou eu ia morar com meu namorado ou ficava na rua"

M 16 - "Estou melhor agora porque ninguém controla minha vida"

M 18- "Ficar grávida foi a único jeito de solucionar meus problemas". 23

As desigualdades de gênero também foram relatadas na pesquisa desenvolvida por Hoga, muitas meninas afirmaram que ficaram grávidas por desejo do parceiro de ser pai e alguns deles as proibiam de tomar pílulas. Elas expuseram também que eles não utilizavam preservativo na

19 Ibidem, p. 57.

20 Ibidem, p. 57.

21 SANTOS, C.A; NOGUEIRA, K.T. Op. Cit..2009

22 PERSONA, Lia; SHIMO, Antonieta Keiko Kakuda; TARALlO, Maria Celina. Perfil de adolescentes com repetição da gravidez atendidas num ambulatório de pré-natal. Revista Latino-Americana de Enfermagem. Ribeirão Preto, v. 12. n. 5. p. 745-750, set./out. 2004. DOI: http://dx.doi.org/10.1590/S0104-11692004000500007. Disponível em:<http://www. scielo.br/scielo.php?script=sci_arttext\&pid=S0104-11692004000500007\&lng=en\&nrm=iso >. Acesso em: 09 jun. 2020.

23 HOGA, Luiza Akiko Komura. Maternidade na adolescência em uma comunidade de baixa renda: experiências reveladas pela história oral. Rev. Latino-Americana de Enfermagem. São Paulo, v. 16, mar./abr. 2008. Disponível em: < https://www. scielo.br/scielo.php?pid=S0104-11692008000200017\&script=sci_abstract\&tlng=pt >. Acesso em: 10 jun. 2020. 
relação sexual e que nunca conversaram com elas sobre o uso de anticoncepcionais, demonstrando descaso quanto aos métodos contraceptivos. ${ }^{24}$

Há uma atribuição cultural da contracepção à mulher desde o surgimento da pílula, e a gravidez por descuido fica como responsabilidade estritamente feminina, como um castigo por não utilizar métodos contraceptivos, excluindo totalmente o papel masculino na concepção. Muitos meninos tentam eximir-se do dever de pai, afirmando que "[...] "não se preocupou com isso, pois a responsabilidade da contracepção é da parceira [...]". ${ }^{25}$

A desestruturação, os conflitos familiares e o abuso sexual, também foram atribuídos como causas para as adolescentes saírem de casa e utilizarem a gravidez como pretexto. A constituição de uma família precocemente é uma forma de solução para os problemas, algumas meninas comentaram que sair de suas casas também representou um certo tipo de liberdade para gerir suas vidas. ${ }^{26}$

Eu não tinha outra opção: ou ficava com meu namorado ou na rua, eu não me arrependo por ter tido um filho, eu estou vivendo melhor; Ficar grávida e ir morar com meu namorado foi um meio de eu ir embora de casa, com meu namorado, eu encontrei tudo: liberdade, atenção, respeito, valorização. ${ }^{27}$

A gravidez na adolescência encontra diversos aliados para sua reprodução, criando um ciclo intergeracional de gravidez na adolescência, tendo em vista que as mães de meninas grávidas também foram mães adolescentes e não conseguiram, mesmo reprovando a gravidez precoce, fazer com que suas filhas tomassem outro rumo. Além dos fatores sócio-culturais e de reprodução de vida familiar, há os recortes econômicos, educacionais e territoriais que criam a vontade de ser mãe em milhares de meninas todos os dias.

As adolescentes reclamam do preconceito dos especialistas quanto à vontade natural de ser mãe, contrariando o paradigma da gravidez precoce como um problema. As meninas também apontaram que a percepção da gravidez na adolescência somente como um problema e/ ou vulnerabilidade social acabam por afastá-las das políticas públicas e do âmbito educacional. ${ }^{28} \mathrm{~A}$ atenção especializada oferecida pelos profissionais de saúde demonstra-se de grande importância para as adolescentes, pois é uma forma de acolhê-las e oferecer algum tipo de dignidade e respeito, fatores considerados muito importante por elas.

A cultura predominante problematiza a gravidez na adolescência, e a julga sob a ótica da vulnerabilidade social. Contudo, milhares de meninas que tiveram a experiência da gravidez precoce tem um discurso diverso, que aponta a gravidez como um momento de ressignificação de suas vidas e amadurecimento, como também como um tipo de solução para seus problemas familiares.

24 Ibidem.

25 SANTOS, C.A; NOGUEIRA, K.T. Op. Cit..2009, p. 54.

26 HOGA, Luiza Akiko Komura; BORGES, Ana Luiza Vilella; REBERTE, Luciana Magnoni. Razóes e reflexos da gravidez na adolescência: narrativas dos membros da família. Escola Anna Nery. Rio de Janeiro, v. 14, n. 1. p. 151-157, mar. 2010. DOI: https://doi.org/10.1590/S1414-81452010000100022. https://www.redalyc.org/pdf/393/39348246002.pdf Disponível em: <http://www.scielo.br/scielo.php?script=sci_arttext\&pid=S1414-81452010000100022\&lng=pt\&nrm=i so>. Acesso em: 20 jun. 2020.

27 Ibidem.

28 SANTOS, B.R. Op. Cit..2017 
Se faz necessário analisar o contexto da gravidez precoce dentro de múltiplas realidades e enfoques de classe, raça e gênero, para a partir daí retirar os fatores de risco que permeiam a reprodução na adolescência e elaborar uma série de medidas para prevenção e conscientização sobre todos os aspectos de "ter um filho".

Se pode observar que a maioria das meninas grávidas e mães que participaram das inúmeras pesquisas, não tem perspectivas de um futuro melhor e muito menos informaçáo e acesso a anticoncepcionais e preservativos para prevenir a gravidez. Torna-se muito fácil julgar a gravidez precoce como um desvio da adolescência, porém é muito complexo colocar-se no lugar das meninas e tomar decisóes no contexto sócio-cultural, afetivo e econômico em que elas vivem. Por isso, a gravidez deve ser repensada e as estratégias para sua prevenção devem ser ampliadas, abordando também as questóes emocionais e culturais que levam uma adolescente a desejar ser mãe.

\section{Impactos sócio familiares da gravidez na adolescência}

A gravidez precoce implica em diversas questôes que transpóem o papel de mãe, vindo acompanhada, inúmeras vezes, de uma união conjugal, de mudança de residência, de abandono escolar e afastamento do trabalho, fazendo com que adolescentes, que vivem em um período atípico de desenvolvimento, tenham que assimilar novas responsabilidades a partir da gravidez.

A partir disto, a análise da gravidez precoce associada ao papel social demonstra sua relevância, quando se observa que a maioria das meninas grávidas pertencem a classes baixas e tem uma tendência a reproduzir o modo de vida de seus antepassados. As desigualdades de gênero também são legitimadas pelo baixo ou inexistente poder econômico da menina na família, uma vez que inúmeras meninas antes ou após a gravidez não conseguem concluir o ensino fundamental e/ou médio, implicando diretamente nas oportunidades de trabalho; fazendo com que o homem domine emocional e economicamente a relação, reduzindo ainda mais a possibilidade de emancipação das meninas e mulheres.

Normas comuns podem influenciar características sociais como a igualdade entre os sexos, a natureza dos cuidados dispensados aos filhos, o tamanho da família e os padróes de fecundidade, o tratamento do meio ambiente e muitas outras. Os valores prevalecentes e os costumes sociais também pela presença ou ausência de corrupção e pelo papel da confiança nas relaçốes econômicas, sociais ou políticas. O exercício da liberdade é mediado por valores que, porém, por sua vez, são influenciados por discussões públicas e interações sociais, que são, elas próprias, influenciadas pelas liberdades de participação. Cada uma dessas relaçóes merece um exame minucioso. ${ }^{29}$

Das meninas que frequentam a escola, com o advento da maternidade e a necessidade de amadurecimento precoce e responsabilidade por uma nova vida, há desistência dos estudos e as adolescentes passam a se dedicar ao cuidado com o bebê e a trabalhar. Outra mudança visível na maternidade e relatado pela família, além do amadurecimento, é o afastamento de ambientes marginalizados e más companhias, o que faz com que as mães tornem-se, após a gravidez, adolescentes exemplares. ${ }^{30}$

29 SEN, Amartya. Desenvolvimento como liberdade. Tradução de Laura Teixeira Motta. São Paulo: Companhia das Letras, 2010, p. 24.

30 HOGA, L.A.K. Op. Cit..2010 
A pesquisa qualitativa realizada por Hernandéz, ${ }^{31}$ apontou fatores de vulnerabilidade como relaçóes familiares ruins, alcoolismo na família, violência intrafamiliar, abandono escolar antes da gravidez, ingresso no mercado de trabalho antes da gravidez, responsabilidade pelos afazeres domésticos, dentre outros; como elementos de risco para a adolescente e que somente podem ter sido asseverados com a gravidez, afirmando não haver impactos sócio-econômicos provocados diretamente pela gravidez precoce.

Fazendo uma distinção entre gêneros quanto a sociabilidade durante e após a gravidez, as meninas sofrem muito mais com a solidão do que os meninos, tendem a ficar mais presas em casa e com maiores restriçóes para sair por conta do filho e da responsabilidade pelos cuidados com o lar. A redução do convívio social diminui cerca de $73 \%$ para as meninas, enquanto que para meninos diminui cerca de $40 \%$, o que demonstra a mudança radical nas vidas de meninas mães se comparadas a dos pais. ${ }^{32}$

Os impactos de uma gravidez precoce na vida de uma adolescente aumenta consideravelmente quando o pai da criança decide se eximir de qualquer responsabilidade. A corresponsabilidade na maternidade é um dos pontos principais para a reinserção da menina no âmbito educacional e laboral, uma vez que se o pai e/ou companheiro compartilhar as tarefas de cuidado com a criança e do lar, a mulher tem a oportunidade de se dedicar a objetivos pessoais.

A conjugalidade também é uma característica da gravidez precoce, mães adolescentes tem maior probabilidade de conviver com seus companheiros, se comparadas a meninas que não engravidaram na adolescência. Santos ${ }^{33}$, faz um estudo com adolescentes que tiveram filhos num período igual ou inferior a dois anos e adolescentes que foram mães a mais de dois anos, e aponta que grande parte das meninas que compóem o primeiro grupo (mães com filhos em período inferior a dois anos) vivem em união conjugal com o pai do bebê, mesmo que não haja preparação para os cuidados com o filho.

Já no grupo de mães com filhos com mais de dois anos, a estatística é invertida, isto é, grande parte das meninas vive com seus familiares, o que pode indicar que a adolescente e seus familiares perceberam que a união conjugal pode não melhorar a condição de vida da adolescente e seu filho, já que a maioria das gravidezes ocorrem em um período de formação da menina e não há uma estrutura psicológica e/ou financeira para a formação de uma família. ${ }^{34}$

[...] a gravidez as insere, de maneira obrigatória, em experiências adultas, o que implica um amadurecimento bem mais antecipado do que o que teriam se náo estivessem esperando um filho. E essa perspectiva advém não apenas delas próprias, mas de pressões dos familiares, pois agora existe uma criança para ser cuidada e educada. ${ }^{35}$

31 HERNÁNDEZ, Gloria Elizabeth García. Embarazo adolescente y pobreza, una relación compleja. Revista de Ciencias Sociales y Humanidades. Iztapalapa, n.77, p.13-53, 2014. ISSN: 0185-4259. Disponível em: https://www.redalyc.org/ articulo.oa?id=393/39348246002.

32 HEILBORN, Maria Luiza. Et. al. Gênero e diversidade na escola: formação de professoras/es em Gênero, Orientação Sexual e Relações Étnico-Raciais. Livro de conteúdo. Rio de Janeiro: CEPESC, 2009. v.2, 98p. ISBN 978-85-89737-12-8. Disponível em: <http://www.e-clam.org/downloads/GDE_VOL2_final.pdf>. Acesso em: 16 jun. 2020.

33 SANTOS, Felícia Mariana. Os impactos da maternidade precoce sobre os resultados socioeconômicos de curto prazo das adolescentes brasileiras. Dissertaçáo (Mestrado em Economia Aplicada). Faculdade de Economia, Administração e Contabilidade de Ribeirão Preto- Universidade de São Paulo, Ribeirão Preto, 2013.

34 SANTOS, F.M. Op. Cit.. 2013

35 PANTOJA, Florinaldo Carreteiro; BUCHER, Júlia Sursis Nobre Ferro; QUEIROZ, Cristiane Holanda. Adolescentes grávidas: vivências de uma nova realidade. Psicol. cienc. prof. Brasília, v. 27, n. 3, p. 510-521, set. 2007. DOI: https://doi.org/10.1590/S1414-98932007000300011.Disponível em: $\quad<$ http://www.scielo.br/scielo.php?script=sci_ 
A adolescente adquire um novo "status" social após a gravidez, adentrando ao mundo adulto, como se adulta fosse, e adquirindo responsabilidades com o filho, com o lar e, não raras vezes, com o casamento. Se a menina decide e/ou precisa ingressar no mercado de trabalho para custear sua sobrevivência e de seu filho, ser contratada é uma tarefa duplamente difícil sendo uma adolescente, sem qualificação e com filhos; o que faz com que essas meninas aceitem trabalhos informais e com baixa remuneração, o que auxilia na manutenção da pobreza familiar.

A maternidade na adolescência vivida no seio familiar, também impacta nas relaçóes com os membros da família, na dinâmica familiar e na vida das adolescentes. Em geral, a família responde de forma positiva a gravidez precoce, embora de início tenha reprovado, pelo fato de "desviar" o caminho das adolescentes. Adaptações financeiras e físicas também são fatores apontados pela família, "foi difícil, mexeu com a estrutura da família ... Reformamos a casa para acomodar a criança." 36

Em uma análise realizada por Santos e $\operatorname{Schor}^{37}$ com adolescentes de classe baixa no Rio de Janeiro, tendo como principal questionamento "Sua vida hoje é melhor ou pior do que antes de ficar grávida? Por quê?", $70 \%$ das meninas afirmaram que sua vida era melhor antes de engravidar, é interessante observar que as adolescentes que afirmaram que suas vidas estavam piores, pertencem a famílias pobres, o que indica problemas financeiros advindos da gravidez precoce não planejada.

Mesmo as adolescentes que planejaram engravidar, afirmaram que suas vidas eram melhores antes da maternidade. Dentre os fatores sociais negativos, as adolescentes afirmaram que ter um filho cedo, fez com que elas perdessem sua juventude; e que muitas pessoas ficam olhandoas com anormalidade, por serem mães adolescentes. Além disso, as adolescentes demonstram-se preocupadas quanto ao seu futuro e de seu filho, algumas delas afirmaram a vontade de sumir e outras apontaram que seu filho ficaria melhor se fosse criado por outra pessoa. ${ }^{38}$

A família das adolescentes grávidas sentem-se impotentes diante do acontecimento da gravidez, lamentando pela interrupçáo dos projetos de vida das meninas e afirmando que com um filho será muito mais difícil sua inserção ou retorno a escola e ao trabalho. Embora a gravidez precoce não agrade os familiares, após algum tempo muitos passam a agir de forma solidária para com a adolescente, a fim de dar subsídios para que ela retome a vida que tinha antes de ser mãe.

Do ponto de vista das expectativas sociais que recaem sobre essa etapa vital, prevê-se que, idealmente ao menos, o investimento maior esteja alocado na carreira escolar, entendida como pré-requisito para uma inserção no mercado de trabalho em melhores condições. Essa passagem possibilitaria a emancipação do jovem frente à sua família de origem, permitindo, simultaneamente, a constituição de sua própria casa e família. Uma vez completadas essas transiçôes, ter-se-ia a entrada do jovem na vida adulta. Contudo, o sentido linear, previsto nesse modelo, reveste-se, na atualidade, de algumas complicações, redundando no que se designa de prolongamento da juventude. ${ }^{39}$

arttext\&pid=S1414-98932007000300011\&lng=en\&nrm=iso >. Acesso em: 07 jun. 2020. p. 517.

36 HOGA, L.A.K. Op. Cit..2010, p. 154.

37 SANTOS, Sílvia Reis dos; SCHOR, Néia. Vivências da maternidade na adolescência precoce. Rev. Saúde Pública. São Paulo, v.37, n.1, p.15-23, 2003. DOI: https://doi.org/10.1590/S0034-89102003000100005. Disponível em: https:// www.scielo.br/scielo.php?pid=S0034-89102003000100005\&script=sci_abstract\&tlng=pt. Acesso em 1 jul. 2020.

38 Ibidem.

39 HEILBORN, Maria Luiza. et al. Aproximaçôes socioantropológicas sobre a gravidez na adolescência. Horizontes antropológicos. Porto Alegre, v. 8, n. 17, p. 13-45, jun. 2002. DOI: https://doi.org/10.1590/S0104-71832002000100002. Disponível em <http://www.scielo.br/scielo.php?script=sci_arttext\&pid=S0104-71832002000100002\&lng=pt\&nrm=i 
A gravidez na adolescência também impacta significativamente as questôes emocionais e psicológicas das adolescentes, podendo asseverar conflitos familiares, quando a gravidez não foi planejada e a adolescente não tem apoio familiar. As constantes mudanças físicas, biológicas e estéticas provocadas pela adolescência e pela gravidez, causam instabilidades emocionais e um sentimento de que a partir do momento que a criança nasce, a adolescente deve transformar-se em adulta e assumir diversas responsabilidades. ${ }^{40}$

Os principais impactos sociais da gravidez precoce, a partir da visão das mães adolescentes, das famílias e dos pesquisadores, foi o abandono escolar, a perda de oportunidades educacionais e profissionais e a transposição da fase adolescente. As desigualdades de classes e gênero também são fatores que influenciam demasiadamente nas trajetórias de vida das adolescentes mães, sendo que meninas pertencentes a classes pobres sofrem impactos diretamente, uma vez que reduzem as já limitadas oportunidades de mobilidade social.

\section{Problemas econômicos advindos da gravidez na adolescência a partir da perspectiva de classe, gênero e raça}

Se faz necessário realizar alguns recortes econômicos, de gênero e raciais para compreender a amplitude da gravidez na adolescência. A proporção de meninas grávidas com renda per capita muito baixa chega a ser seis vezes maior do que em meninas com renda per capita alta, e quanto menor o grau de escolarização, maior a proporção de gravidez precoce; meninas pretas e pardas representam mais de $70 \%$ das meninas grávidas e mães, e também compõem a grande maioria de meninas com menor renda e escolaridade. ${ }^{41}$

Diversas meninas que participaram da pesquisa realizada por Hoga ${ }^{42}$, afirmaram que a gravidez precoce e a impossibilidade de continuar estudando, representou uma "exclusão de sonhos" em suas vidas. Dentre os maiores sonhos das adolescentes após serem mães, estavam a possibilidade de sustento próprio e de seus filhos como um futuro melhor para ambos, para evitar que os filhos cometessem os mesmos erros e enfrentassem os problemas financeiros vivenciados por elas.

Há teses que defendem a gravidez na adolescência como causa da pobreza e outras, contrariamente, afirmam que a gravidez é somente um agravamento da pobreza preexistente e que questóes como falta de oportunidades e incentivo seriam as maiores responsáveis pela situação de marginalidade social. ${ }^{43}$

A escola é considerada um dos grandes pilares de crescimento e desenvolvimento para crianças e adolescentes. Contudo, esse ambiente reforça, por vezes, a segregação de classes e raças, privilegiando os brancos e ricos e corroborando com o sentimento de fracasso dos pretos/

so>. Acesso em: 30 jun. 2020. p. 21.

40 TABORDA, Joseane Adriana; et. al. Consequências da gravidez na adolescência para as meninas considerando-se as diferenças socioeconômicas entre elas. Cadernos de saúde coletiva. Rio de Janeiro, v.22, n.1, p.16-24, jan./mar. 2014. DOI: https://doi.org/10.1590/1414-462X201400010004. Disponível em: <http://www.scielo.br/scielo.php?script=sci_ arttext\&pid=S1414-462X2014000100016\&lng=pt\&nrm=iso >. Acesso em: 2 jul. 2020.

41 HEILBORN, M.L. Op. Cit.. 2009

42 HOGA, L.A.K. Op. Cit..2008

43 HERNÁNDEZ, M.L. Op. Cit..2014. 
pardos e pobres. Segundo Hernandéz ${ }^{44}$, "las experiencias de fracaso escolar les confirman sus limitaciones, a la vez que el contexto de pobreza les muestra que, si bien estudiar es importante y socialmente valorado, no es un proyecto al que ellas puedan aspirar.

A condição de exclusão do ambiente educacional se dá desde muito antes da gravidez, não raras vezes, as meninas já haviam reprovado e/ou trocado de escola por dificuldades em aprendizagem ou sentimento de não pertencimento, ou seja, os fatores que afastam as meninas do estudo, como a necessidade de trabalhar para contribuir com a renda familiar ou a necessidade de cuidado de familiares. A exclusão escolar constitui apenas um dos aspectos da exclusão social mais ampla vivenciada pelas meninas. ${ }^{45}$

Essa realidade também é apontada por Heilborn ${ }^{46}$ no Brasil, onde inúmeras meninas que vivem em contexto de pobreza e marginalização, abandonam a escola antes de engravidarem. A pesquisa de Heilborn ${ }^{47}$, também aponta que meninas entre 15 e 18 anos possuem responsabilidades domésticas, o que também acaba prejudicando a dedicação aos estudos.

A associação entre maternidade e escolaridade realizada por Santos ${ }^{48}$, demonstrou que meninas mães possuem 18,8 pontos percentuais de probabilidade de frequentar a escola, e meninas que não sofreram com essa adversidade, provavelmente tem escolhas bem diferentes em relação as que tem filhos. $\mathrm{O}$ atraso escolar que as mães adolescentes apresentam, evidencia os prejuízos educacionais a curto prazo, o que pode vir a refletir em suas escolhas e oportunidades a longo prazo.

A análise transversal de gêneros, aponta que houve uma espécie de "atualização ideológica" de gêneros, onde a mulher passou a ocupar o papel de trabalhadora e de ser independente, permitindo com que se criasse a categoria da dupla jornada, que além de explorar a mulher, auxilia no aprofundamento das desigualdades sociais de gênero. Os trabalhos atribuídos culturalmente as mulheres e, normalmente, mal pagos ou não reconhecidos, também corroboram com a feminização da pobreza. As famílias monoparentais, com somente a mãe como provedora do lar, vem crescendo significativamente nos últimos anos no mundo, o que implica na acumulação de tarefas e impede o desenvolvimento feminino. ${ }^{49}$

Os impactos socioeconômicos de curto prazo na vida de mães adolescentes, envolvem o agravamento das vulnerabilidades, o que a longo prazo intensifica as diferenças sociais, raciais e de gênero. A baixa escolaridade está intrinsicamente associada a gravidez precoce, Santos ${ }^{50}$ observou que a maioria das meninas mães, interromperam seus estudos no ensino fundamental e não retornaram mais. Em relação ao ingresso no ensino superior, a proporção de mulheres mães na adolescência é cerca de três vezes menor em comparação a grupos de mulheres que não engravidaram precocemente.

44 Ibidem, p. 17.

45 Ibidem.

46 HEILBORN, M.L. Op. Cit..2009

47 Ibidem

48 SANTOS, F.M. Op. Cit..2013

49 GIFFIN, Karen. Pobreza, desigualdade e equidade em saúde: consideraçóes a partir de uma perspectiva de gênero transversal. Cadernos de Saúde Pública. Rio de Janeiro. v. 18, p. 103-112, jul./set. 2002. DOI: https://doi.org/10.1590/ S0102-311X2002000700011. Disponível em <http://www.scielo.br/scielo.php?script=sci_arttext\&pid=S0102-311X2002 $000700011 \& \operatorname{lng}=$ pt\&nrm=iso $>$. Acesso em: 18 jun. 2020.

50 SANTOS, F.M. Op. Cit..2013 
Nas características de mercado de trabalho e ocupacionais, a presença de filhos na adolescência tende a prejudicar seu engajamento no mercado de trabalho. A diferença salarial entre os dois grupos é de, aproximadamente, 288 reais. O desemprego também é maior para as mulheres que foram mães na adolescência. ${ }^{51}$

A gravidez precoce e a condição social também deve ser associada a cor de pele, uma vez que a maior parcela de pessoas que compóem as classes sociais e concentram o maior número de gravidezes na adolescência são pessoas negras e pardas, o que permite constatar que a gravidez na adolescência é uma característica de pessoas negras/pardas e pobres. ${ }^{52}$

As dificuldades de inserção educacional e laboral, por vezes é superada, quando a adolescente encontra apoio na família e no companheiro. Na pesquisa realizada com máes adolescentes, Santos ${ }^{53}$ constatou que, apesar do abandono escolar durante a gravidez ou depois que o bebê nasce, as meninas conseguem se reintegrar a escola posteriormente. Contudo, o desenvolvimento dessas adolescentes máes depende de uma rede de apoio que auxilie nos cuidados com o filho e incentive a menina a progredir.

Las evidencias de que el embarazo durante la adolescencia muchas veces trunca posibilidades de desarrollo y pérdida de un proyecto de vida, han sido mostradas en diversos contextos de México y de América Latina [...] Esto se debe precisamente a la especificidad del contexto, puesto que el embarazo adolescente tiene características particulares que no necesariamente se dan en otros lugares: los adolescentes no conforman grupos homogéneos; por el contrario, su diversidad es tan amplia que es imposible generalizar dichos comportamientos al total de este grupo etario. ${ }^{54}$

A feminização da pobreza cresce em contextos latino-americanos, uma vez que além da pobreza, há fatores sociais, culturais e de gênero que corroboram com a submissão da mulher ao âmbito estritamente familiar e doméstico. Reyes e Almontes, ${ }^{55}$ ressaltam que as mulheres latino-americanas são as que possuem os níveis mais altos de atraso e abandono escolar, seja pela situação de precariedade socioeconômica, como também pelo padrão cultural que valoriza mais a escolaridade masculina e considera que o papel das mulheres deve se limitar a reprodução humana e ao ambiente doméstico.

A proporção de meninas já afastadas da escola antes da gravidez e as que se afastam quando engravidam, faz surgir questionamentos sobre o processo de escolarizaçáa de crianças e adolescentes. A escola deve propiciar ambientes adequados para manter as adolescentes estudando, independentemente de suas condiçóes maritais ou reprodutivas, pois se tem observado que não é a questão gestacional, única e exclusivamente, a causadora de abandono escolar, e sim as condições socioeconômicas constam como os principais motivos para afastamento escolar. ${ }^{56}$

Os projetos educacionais e profissionais voltados a meninas economicamente marginalizadas, tem se demonstrado incapazes de apresentar alternativas suficientemente

51 SANTOS, F.M. Op. Cit..2013, p. 16.

52 Ibidem.

53 Ibidem.

54 REYES, David De Jesus; ALMONTES, Esmeralda González. Elementos teóricos para el análisis del embarazo adolescente. Sexualidad, Salud y Sociedad. Rio de Janeiro, n. 17, p. 98-123, mai./ago. 2014. DOI: https:// doi.org/10.1590/1984-6487.sess.2014.17.07.a. Disponível em <http://www.scielo.br/scielo.php?script=sci_ arttext\&pid=S1984-64872014000200098\&lng=pt\&nrm=iso $>$. Acesso em: 27 jun. 2020. p. 101.

55 Ibidem.

56 Ibidem. 
atraentes para que elas descartem o desejo pela maternidade precoce. Enquanto milhares de mulheres adiam a gravidez para dar prioridade aos projetos e ascensão profissionais em busca de estabilidade, o mesmo não ocorre na vida de meninas com baixas condiçóes econômicas. "Muitas vezes, premidas pela necessidade, frequentam pouco a escola e precisam trabalhar para colaborar com a renda familiar." 57

"Espera-se que as jovens dos diferentes estratos sociais terminem seus estudos e adquiram uma estabilidade profissional, como se esse ideal fosse acessível a todas. ${ }^{" 58} \mathrm{~A}$ visão dos especialistas muitas vezes se dá a partir de adolescentes de classe média ou alta, o que interfere nas pesquisas e na expectativa dos profissionais quanto ao futuro das adolescentes com gravidez precoce.

Apesar da gravidez precoce representar a interrupção nos planejamentos de adolescentes e na expectativa da família por um futuro melhor, pesquisas apontam que a mulher, independentemente de engravidar durante a adolescência ou na vida adulta, ficará prejudicada no mercado de trabalho. $\mathrm{O}$ que demonstra a existência de desigualdades de gênero no mercado de trabalho, favorecendo a figura masculina, pois a mulher com filhos, possuindo ou náo uma relação marital, é vista como menos capaz do que um homem, solteiro ou casado, com filhos ou sem filhos. ${ }^{59}$

$\mathrm{O}$ que varia entre mulheres que planejam e as que não planejam engravidar, é a escolarizaçáo e consequentemente o posto ocupado no mercado de trabalho. As adolescentes sofrem muito mais impactos socioeconômicos do que mulheres adultas que já alcançaram algum tipo de formação e já possuem estabilidade laboral. Contudo, o fator da desigualdade entre gêneros atinge os dois grupos, a adolescente por não conseguir se (re)inserir no ambiente escolar e laboral e a mulher adulta por ter de, por vezes, optar pela ascensão profissional ou ser mãe.

A adolescência percebida pela perspectiva superficial, não abrange os recortes de raça e classe social, fatores determinantes à trajetória das adolescentes. Meninas negras e pobres tem projetos de vida e oportunidades distintas de meninas brancas de classe média ou alta, essas condiçôes variáveis se dão tanto pelas marcantes desigualdades sociais existentes em países de capitalismo periférico, como o Brasil, como também pelas ideologias de gênero e cultura engendradas socialmente.

Diante de certos contextos econômicos e posiçóes das adolescentes na estrutura social, há condiçôes que favorecem e impedem a gravidez na adolescência e determinam os impactos da maternidade no futuro dessas meninas. Entre as disparidades econômicas e as de gênero, as de gênero tem se demonstrado muito mais fortes. "Essas questôes assumem relevância em uma sociedade como a brasileira, caracterizada por um fosso significativo, senão intransponível, entre classes sociais, e pela persistência das diferenças entre o masculino e o feminino.” ${ }^{60}$

57 NUNES, Silvia Alexim. Esperando o futuro: a maternidade na adolescência. Physis. Rio de Janeiro, v. 22, n. 1, p. 5375, 2012 . DOI: http://dx.doi.org/10.1590/S0103-73312012000100004. Disponível em: <http://www.scielo.br/scielo. php?script=sci_arttext\&pid=S0103-73312012000100004\&lng=pt\&nrm=iso $>$. Acesso em: 21 jun. 2020. p. 65 .

58 Ibidem, p. 65.

59 SOUZA, Laetícia Rodrigues de; RIOS-NETO, Eduardo Luiz Gonçalves; QUEIROZ, Bernardo Lanza. A relação entre parturição e trabalho feminino no Brasil. Revista brasileira de estudos de população. São Paulo, v. 28. n. 1, p. 57-79, jan./ jun. 2011. DOI: https://doi.org/10.1590/S0102-30982011000100004. Disponível em: <http://www.scielo.br/scielo. php?script=sci_arttext\&pid=S0102-30982011000100004\&lng=en\&nrm=iso >. Acesso em: 29 jun. 2020.

60 HEILBORN, M.L. Op. Cit..2002, p. 25. 
Das adolescentes que se tornam mães, as de classes menos favorecidas são as que sofrem mais impactos com a gravidez. Na pesquisa realizada por Taborta et. al ${ }^{61}$, com mães adolescentes pertencentes a diversos estratos sociais, as meninas das classes mais pobres, são as que mais relataram dificuldades a partir da chegada do bebê, quanto ao abandono escolar, uma das meninas relata: "Tenho até vontade de voltar a estudar, mas agora não tem como, mas assim que a minha filha crescer um pouco mais eu volto (C3 classe C)" ${ }^{62}$, o discurso altera-se completamente quando se trata de uma adolescente da classe A.

Meus pais não queriam que eu parasse de estudar de maneira nenhuma, mas quando a barriga começou a aparecer... Senti que minhas colegas me olhavam de outra maneira, algumas até se afastaram, senti muita vergonha. Então resolvi parar (...). Quando a bebê nasceu meus pais contrataram uma babá e eu pude voltar... (A2 classe A). ${ }^{63}$

A gravidez precoce, mesmo ocorrendo em todas as camadas sociais, impacta desproporcionalmente mais, a vida de meninas, negras e pobres; e as repercussóes dessa série de privaçôes de renda, escolaridade e sociabilidade, cria o ciclo de pobreza extrema e faz com que o Brasil, cada vez mais, seja um país reconhecido pelas desigualdades sociais e pela feminização da pobreza de mulheres, negras e pobres.

\section{Conclusáo}

A gravidez na adolescência sob a perspectiva de problema sociofamiliar e de saúde, vem fazendo com que pesquisadores de diversas áreas questionem-se o motivo de haver tantas meninas grávidas num vasto contexto de informação e universalização de métodos anticoncepcionais. A adolescência atual, que têm acesso à internet e que utiliza smartphones, parece os um tanto avançada quando comparada a juventude dos anos 90.

Contudo, há que se considerar os recortes de classe, gênero e raça dentro da adolescência, para compreender a cultura, a trajetória familiar e as oportunidades sociais de cada grupo. Os determinismos inerentes aos adolescentes, definem suas expectativas de futuro e, para algumas meninas, tornar-se mãe é um sonho e uma possibilidade de mudar de status social e econômico.

É necessário repensar o modo como as pesquisas brasileiras são realizadas, a ideologia por detrás do estudo, pois em contextos de marginalização e pobreza, não é possível esperar que um adolescente vá almejar um curso superior ou uma carreira de sucesso, como se espera de adolescentes de classe média e alta. A gravidez precoce, representa em muitos casos, uma maneira de fugir da violência intrafamiliar, da fome, da opressão e também como uma forma de valorização e reconhecimento social.

A presente pesquisa, ao constatar que a maioria das meninas-mães pertencem a classe pobre, não concluíram o ensino fundamental ou médio e são negras ou pardas, adotou novas lentes, considerando as expectativas possíveis para esses grupos, tendo em vista que as oportunidades educacionais e de trabalho são limitadas no Brasil, devido ao racismo estrutural, a pobreza e a segregação de gêneros.

61 TABORDA, J.A. et al. Op. Cit..2014

62 TABORDA, J.A. et al. Op. Cit..2014, p. 19.

63 Ibidem. 
Todos esses fatores associados à gravidez na adolescência, excluem meninas e mulheres da economia brasileira, afetando sua emancipaçáo e sua liberdade, formando um ciclo de pobreza feminino ou a feminizaçáo da pobreza, que atinge tanto as meninas e mulheres como seus filhos, perpetrando a pobreza através das geraçóes.

Portanto, a gravidez na adolescência como uma vontade da adolescente ou um descuido, somente assevera o contexto de pobreza e restringe, ainda mais, as limitadas oportunidades que meninas, negras e pobres, têm acesso. A realidade brasileira de desigualdade social e capitalismo periférico necessita ser modificada e as políticas públicas de prevenção e justiça social são a chave principal para mudança.

\section{Referências}

COSTA, M. M. Moraes. A Transversalidade das Políticas Públicas na Perspectiva de Gênero. Direitos Sociais e Politicas Públicas: desafios contemporâneos. Santa Cruz do Sul - EDUNISC, 2011.

GIFFIN, Karen. Pobreza, desigualdade e equidade em saúde: consideraçóes a partir de uma perspectiva de gênero transversal. Cadernos de Saúde Pública. Rio de Janeiro. v. 18, p. 103112, jul./set. 2002. DOI: https://doi.org/10.1590/S0102-311X2002000700011. Disponível em <http://www.scielo.br/scielo.php?script=sci_arttext\&pid=S0102-311X2002000700011\&ln $\mathrm{g}=\mathrm{pt} \& \mathrm{nrm}=\mathrm{iso}>$. Acesso em: 18 jun. 2020.

HEILBORN, Maria Luiza. et al. Aproximaçôes socioantropológicas sobre a gravidez na adolescência. Horizontes antropológicos. Porto Alegre, v. 8, n. 17, p. 13-45, jun. 2002. DOI: https://doi.org/10.1590/S0104-71832002000100002. Disponível em <http://www.scielo.br/ scielo.php?script $=$ sci_arttext\&pid $=S 0104-71832002000100002 \& \operatorname{lng}=p t \& n r m=i s o>$. Acesso em: 30 jun. 2020.

HEILBORN, Maria Luiza. Et. al. Gênero e diversidade na escola: formação de professoras/es em Gênero, Orientação Sexual e Relaçôes Étnico-Raciais. Livro de conteúdo. Rio de Janeiro: CEPESC, 2009. v.2, 98p. ISBN 978-85-89737-12-8. Disponível em: <http://www.e-clam. org/downloads/GDE_VOL2_final.pdf>. Acesso em: 16 jun. 2020.

HEILBORN, Maria Luiza. et. al. O aprendizado da sexualidade: reprodução e trajetórias sociais de jovens brasileiros. Rio de Janeiro: Garamond e Fiocruz, 2006.

HERNÁNDEZ, Gloria Elizabeth García. Embarazo adolescente y pobreza, una relación compleja. Revista de Ciencias Sociales y Humanidades. Iztapalapa, n.77, p.13-53, 2014. ISSN: 0185-4259. Disponível em: https://www.redalyc.org/articulo.oa?id=393/39348246002.

HOGA, Luiza Akiko Komura. Maternidade na adolescência em uma comunidade de baixa renda: experiências reveladas pela história oral. Rev. Latino-Americana de Enfermagem. São Paulo, v. 16, mar./abr. 2008. Disponível em: < https://www.scielo.br/scielo.php?pid=S0104$11692008000200017 \&$ script=sci_abstract\&tlng=pt >. Acesso em: 10 jun. 2020. 
HOGA, Luiza Akiko Komura; BORGES, Ana Luiza Vilella; REBERTE, Luciana Magnoni. Razóes e reflexos da gravidez na adolescência: narrativas dos membros da família. Escola Anna Nery. Rio de Janeiro, v. 14, n. 1. p. 151-157, mar. 2010. DOI: https://doi.org/10.1590/ S1414-81452010000100022. https://www.redalyc.org/pdf/393/39348246002.pdf Disponível em: <http://www.scielo.br/scielo.php?script=sci_arttext\&pid=S1414-81452010000100022\&ln g=pt\&nrm=iso $>$. Acesso em: 20 jun. 2020.

NETO, Francisco Rosemiro Guimarães Ximenes; et al . Gravidez na adolescência: motivos e percepçôes de adolescentes. Revista brasileira de enfermagem. Brasília, v. 60, n. 3, p. 279285, mai./jun. 2007. DOI: https://doi.org/10.1590/S0034-71672007000300006. Disponível em:<http://www.scielo.br/scielo.php?script=sci_arttext\&pid=S0034-71672007000300006\&ln $\mathrm{g}=\mathrm{en} \& \mathrm{nrm}=\mathrm{iso}>$. Acesso em: 7 jun. 2020.

NUNES, Silvia Alexim. Esperando o futuro: a maternidade na adolescência. Physis. Rio de Janeiro, v. 22, n. 1, p. 53-75, 2012 . DOI: http://dx.doi.org/10.1590/S010373312012000100004. Disponível em: <http://www.scielo.br/scielo.php?script=sci_ arttext\&pid=S0103-73312012000100004\&lng=pt\&nrm=iso $>$. Acesso em: 21 jun. 2020.

NUNES, Silvia Alexim. Problematizando a gravidez na adolescência. Revista Epos. Rio de Janeiro, v. 1, n. 1, jan. 2010. Disponível em <http://pepsic.bvsalud.org/scielo.php?script=sci_ arttext\&pid=S2178-700X2010000100004\&lng=pt\&nrm=iso>. Acesso em: 25 abr. 2020.

PANTOJA, Florinaldo Carreteiro; BUCHER, Júlia Sursis Nobre Ferro; QUEIROZ, Cristiane Holanda. Adolescentes grávidas: vivências de uma nova realidade. Psicol. cienc. prof. Brasília, v. 27, n. 3, p. 510-521, set. 2007 . DOI: https://doi.org/10.1590/ S1414-98932007000300011.Disponível em: <http://www.scielo.br/scielo.php?script=sci arttext\&pid=S1414-98932007000300011\&lng=en\&nrm=iso >. Acesso em: 07 jun. 2020.

PERSONA, Lia; SHIMO, Antonieta Keiko Kakuda; TARALLO, Maria Celina. Perfil de adolescentes com repetição da gravidez atendidas num ambulatório de pré-natal. Revista Latino-Americana de Enfermagem. Ribeirão Preto, v. 12. n. 5. p. 745-750, set./out. 2004. DOI: http://dx.doi.org/10.1590/S0104-11692004000500007. Disponível em:<http://www. scielo.br/scielo.php?script=sci_arttext\&pid=S0104-11692004000500007\&lng=en\&nrm=iso >. Acesso em: 09 jun. 2020.

PROFISSÃO REPÓRTER. Direção de Ali Kamel e Silvia Faria. Acre: Rede Globo, 2017, (17 min). Disponível em: <https://globoplay.globo.com/v/6340150/>. Acesso em 5 jun. 2020.

RESTA, Darielli Gindri; et. al. Adolescentes: por quais motivos elas engravidam?. Revista de enfermagem UFPE. Recife, v. 8, n. 5, p. 1229-1236, mai. 2014. DOI: 10.5205/ reuol.5863-50531-1-ED.0805201417. Disponível em: <https://periodicos.ufpe.br/revistas/ revistaenfermagem/article/viewFile/9804/9971>. Acesso em: 7 jun. 2020.

REYES, David De Jesus; ALMONTES, Esmeralda González. Elementos teóricos para el análisis del embarazo adolescente. Sexualidad, Salud y Sociedad. Rio de Janeiro, n. 17, p. 98123, mai./ago. 2014. DOI: https://doi.org/10.1590/1984-6487.sess.2014.17.07.a. Disponível em <http://www.scielo.br/scielo.php?script=sci_arttext\&pid=S1984-64872014000200098\&ln $\mathrm{g}=\mathrm{pt \& nrm}=\mathrm{iso}>$. Acesso em: 27 jun. 2020. 
SANTOS, Benedito Rodrigues; et al. Gravidez na adolescência no Brasil: Vozes de meninas e de especialistas. Brasília: Athalaia, 2017. Disponível em: <http://unfpa.org.br/Arquivos/ br_gravidez_adolescencia_2017.pdf>. Acesso em 20 jun 2019.

SANTOS, Cristiane Albuquerque C. dos; NOGUEIRA, Kátia Telles. Gravidez na adolescência: falta de informação?. Adolescência \& Saúde. v. 6, n. 1, p. 48-56, jan./mar. 2009. ISSN: 2177-5281. Disponível em: <https://s3-sa-east-1.amazonaws.com/publisher.gn1.com. br/adolescenciaesaude.com/pdf/v6n1a11.pdf. Acesso em: 25 abr. 2020.

SANTOS, Felícia Mariana. Os impactos da maternidade precoce sobre os resultados socioeconômicos de curto prazo das adolescentes brasileiras. Dissertação (Mestrado em Economia Aplicada). Faculdade de Economia, Administração e Contabilidade de Ribeirão PretoUniversidade de Sáo Paulo, Ribeirão Preto, 2013.

SANTOS, Sílvia Reis dos; SCHOR, Néia. Vivências da maternidade na adolescência precoce. Rev. Saúde Pública. São Paulo, v.37, n.1, p.15-23, 2003. DOI: https://doi. org/10.1590/S0034-89102003000100005.

SEN, Amartya. Desenvolvimento como liberdade. Tradução de Laura Teixeira Motta. São Paulo: Companhia das Letras, 2010.

SOUZA, Laetícia Rodrigues de; RIOS-NETO, Eduardo Luiz Gonçalves; QUEIROZ, Bernardo Lanza. A relação entre parturição e trabalho feminino no Brasil. Revista brasileira de estudos de população. São Paulo, v. 28. n. 1, p. 57-79, jan./jun. 2011. DOI: https://doi. org/10.1590/S0102-30982011000100004. Disponível em: <http://www.scielo.br/scielo. php?script=sci_arttext\&pid=S0102-30982011000100004\&lng=en\&nrm=iso >. Acesso em: 29 jun. 2020.

TABORDA, Joseane Adriana; et. al. Consequências da gravidez na adolescência para as meninas considerando-se as diferenças socioeconômicas entre elas. Cadernos de saúde coletiva. Rio de Janeiro, v.22, n.1, p.16-24, jan./mar. 2014. DOI: https://doi.org/10.1590/1414462X201400010004. Disponível em: <http://www.scielo.br/scielo.php?script=sci_ arttext\&pid=S1414-462X2014000100016\&lng=pt\&nrm=iso $>$. Acesso em: 2 jul. 2020.

UNFPA. Situação da população mundial 2019: Um trabalho inacabado: a busca por direitos e escolhas para todos e todas. Brasil: 2019. Disponível em: <https://brazil.unfpa.org/pt-br/ publications/situacao-da-populacao-mundial-2019>. Acesso em: 22 jun. 2020. 